\title{
The Meaning of Participation: Reflections on Our Study
}

\author{
Xanthe Hunt, Leslie Swartz, Stine Hellum Braathen, \\ Mark T. Carew, Mussa Chiwaula, and Poul Robleder
}

\section{'Nothing Aвout Us Without Us'}

Article 23 of the United Nations Convention for the Rights of Persons with Disability (UNCRPD) emphasises the importance of the equal participation of people with disabilities in all areas of life, and the need

X. Hunt $(\varangle)$

Department of Psychology, Faculty of Arts and Social Sciences, Stellenbosch University, Stellenbosch, South Africa

Institute for Life Course Health Research, Department of Global Health, Faculty of Medicine and Health Sciences, Stellenbosch University, Stellenbosch, South Africa

L. Swartz

Department of Psychology, Faculty of Arts and Social Sciences, Stellenbosch University, Stellenbosch, South Africa e-mail: Lswartz@sun.ac.za

S. H. Braathen

Department of Health Research, SINTEF Digital, Oslo, Norway e-mail: stine.h.braathen@sintef.no

(C) The Author(s) 2021

X. Hunt et al. (eds.), Physical Disability and Sexuality, https://doi.org/10.1007/978-3-030-55567-2_10 
for the elimination of 'discrimination against persons with disabilities in all matters relating to marriage, family, parenthood and relationships' (United Nations, 2006). This includes in respect of sexuality and sexual and reproductive health rights. Yet, there is a long way to go for such equality in participation to be realised. As is evident in the earlier chapters of this book, one of the greatest barriers is the negative attitudes and misconceptions of people without disabilities about the sexual needs and experiences of people with physical disabilities.

For equality to be achieved, the voices of people with physical disabilities themselves need to be included, as full participants, in the design, implementation, monitoring and evaluation of national programmes and policies related to sexuality and sexual and reproductive health. However, across the world, many people with disabilities lack knowledge and awareness about, or access to, their sexual and reproductive health and rights. This is even more pronounced in low- and middle-income countries, and accross much of Sub-Saharan Africa. While a lot of work is being done in HIV and sexual and reproductive health generally, there is little representation of disability in mainstream sexual health initiatives. When decisions are made about people with disabilities, they may be made by people without disabilities, and lack input from the people that they effect: people with disabilities themselves.

One of the mottos of the disability rights movement is 'Nothing about us without us' (Charlton, 1998). What this motto means is that it is necessary to bring people with disabilities to the table when it comes to making disability-relevant decisions. Furthermore, mainstream services need to be

\author{
M. T. Carew \\ UCL International Disability Research Centre, Department of Epidemiology \\ and Public Health, University College London, London, UK \\ e-mail: m.carew@ucl.ac.uk \\ M. Chiwaula \\ Southern Africa Federation of the Disabled, Gaborone, Botswana \\ e-mail: mchiwaula@safod.net \\ P. Rohleder \\ Department of Psychosocial and Psychoanalytic Studies, University of Essex, \\ Colchester, UK \\ e-mail: p.rohleder@essex.ac.uk
}


made inclusive, and this can be achieved by including the voices of people with disabilities, and by opening up discussion and advocacy for sexuality and sexual and reproductive health issues. This is not only at programme planning and health policy level, but in research and public education initiatives too.

This book is based on a research project that explored the experiences of people with physical disabilities. The earlier chapters have explored aspects of sexuality, relationships, femininity, and masculinity, and sexual and reproductive health, not just from an academic/research perspective, but through the personal experiences and voices of people with disabilities themselves.

\section{Working Together to Tell Stories}

Research typically involves the collection of data, after which researchers analyse it, and then report the findings in academic journals for other academics and researchers to read and learn from. This is important, and necessary to develop a critical mass of knowledge that can then be drawn on by interested parties to develop further action. But often, the benefits that such research has for the people on the ground, so to speak, takes a long time to develop, and the participants of the particular studies are not typically involved in what happens to the results; what further actions it may inform.

We wanted to do something different with the project upon which this book is based-and with this book. It was important to research what the societal attitudes were towards people with physical disabilities in South Africa, and what the personal experiences of people with physical disabilities were. Our survey of societal attitudes emphasised the need for more information and awareness about the sexuality and sexual experiences of people with disabilities.

However, this study also involved the work, stories, and photographs of people with physical disabilities. This part of the project generated a lot of useful, personal, and emotive data, in addition to powerful images. We wanted to put these to use to inform people-including non-academic readers-generally about what the issues are for people with physical disabilities when it comes to matters of sexuality, relationships, and sexual and reproductive health. A large part of the Disability and Sexuality Project included activities for getting these stories told and 'out there'. This book is one such activity. 
The process of doing something collaborative, like this book, is not a straightforward one. Important questions need to be reflected on-what will the book say? Who is the book for? And perhaps more importantly, who will publish it? This is no ordinary book. We wanted a book that was educational, that was academic in its content, but that also incorporated the personal, everyday stories of the participants we worked for. It is not a typical book for academic publishers. A publisher we initially approached rejected our proposal for the book, stating that to their mind it was not academic enough. We believe that this view, though understandable, is problematic. In-keeping with much contemporary work on disability studies, we believe that it is important to bridge the divides between the 'academic' and the 'popular' - to bring more people into the conversation (Garland-Thomson, 2005; Swartz, van der Merwe, Buckland, \& McDougall, 2012). In our experience (and most members of our team are experienced academic authors) it has in fact been more challenging to us academically to attempt to bridge divides than to write in the traditional academic way. Although it has meant that we omit certain scholarly topics and forego certain theoretical discussion, we have tried to make concepts accessible to a wide audience. You as a reader will be the best judge of the extent to which we have succeeded.

The process of writing the book needed to be thought about. What will the content be? Who will write it and how? It is a collaborative effort between academics and researchers, experienced in writing for academic purposes, and men and women with physical disabilities who have varying experiences of writing, whether for academic or personal purposes. Some had no experience in writing at all. Some chapters are personal stories, while others draw on more academic content. The writers needed time to work at their differing paces and levels of confidence. There are different voices and different styles of writing. To our mind, this is what makes the book interesting, and we hope you, the reader, will agree.

One of the products that we worked on together, academics and participants with physical disabilities, was the production of a short documentary film. The film included personal stories of four individuals, with an overall narration by a fifth individual. More than the book, this required careful consideration of what key messages to tell in this film. The film script was co-created by all involved, telling both stories of exclusion as well as inclusion. The film is available to view for free on our project website: www.disabilityandsexualityproject.com. The film is also available with subtitles for those who use them. 


\section{The Experience of Participating}

What has it been like to participate in a project like this, and work together on this book? For the core research team, it has been a journey of exploration. It has been fascinating, emotional, humbling, exciting, and hard work. For the thirteen people we worked with, this was also a new and exciting experience. At a final workshop marking the end of the formal research study, we invited participants to write their personal reflections and feedback on taking part in the project. This is some of what was written:

"In this study I often forgot that I was a participant because of the learning /benefit /blessing for myself. The immediate value of the project to me, as a participant during the study was tremendous. Even just identifying undersolved issues in my own life - even without starting a formal therapeutic intervention, has been therapeutic participant in the project has encouraged /strengthened my resolve to be an advocate - albeit in an area that does not feel comfortable."

"It's my first time to become a member of such a group and I'm very much proud to participate to such a group that is the reason why I've told myself that I need to share whatever you are expecting to me and that is why I did share my history about my pregnancy being on a wheelchair. Being physically challenged too and by the time my baby has been born, yes I've experienced something new too because the two boys I do have they were born by the time I was walking, so I'm really experiencing something I never experienced before and I experienced that as we are physically challenged we are different too. I do see those who are different to me as I'm within this project and I love to treat each and every one fair, not to be rude and think that I'm better than the others, we are all human beings and we are created by God so we need to respect each other. I did not know that there'll be some people who would like to learn more about myself too and to have an interest to spend time with me and listen to my story and the experience I do have. As much as we are physically challenged we do have different stories too and different lives."

"I feel very good about this project. For me it is the first time to share my feelings about my disability. I've never shared my story with anyone even my family never had time to listen to my feelings. My community as well does not care, at work it is like you are making excuses if you try to explain what is bothering you. It is also a healing session for me because since I 
got involved in the project, I am able to speak out about myself. I'm not ashamed anymore and for me it is also a learning curve especially to meet other people with different disabilities. I feel that the work will also learn that we are also human and get feeling, needs and dreams. It is not about how I look but it's about who I am, not the physical appearance."

"I had no hesitation to share knowing that my contribution would be respected. Continuous communication also meant a lot and privacy was guaranteed until I had given permission. Although I had no problem with use of info it was good that I could feel the positive involvement through the whole process. The project and research portrays in my humble opinion, a true reflection over a broad spectrum of what happens in the lives of persons with disabilities. I have learnt more about other disabilities about views by both male and female and how my experiences differ. However, in the end we all cope with our specific challenges to work towards finding solutions to live with or without finding a special bond in particular a sexual bond.”

“One thing I've learned because of this project is the freedom of expression as a woman. To be out the feminist, particularly the part where we took pictures. There's no words to describe how grateful I am for the opportunity to express my sexuality as a woman without fear without being judged. The pictures component and the interview, there I could tell, I didn't have to worry what people would say."

As these quotes reflect, the positive experience was not just about taking part in the study, but rather participating in a project, and sharing an experience together. For most, participation was not about helping the research team, or helping to take part in research generally, but rather, the hope of using their experience for advocacy, with the hope of bringing about social change. As one person reminded us all:

“It was extremely liberating to discuss sexuality from my perspective without fear of judgement, when the general assumption is that I am not or rather people /society find it difficult to relate to me as a sexual being. This was confirmed to me just last Friday again (3 days ago). I met a woman and we chatted about this and that to pass the time. I briefly mentioned that I have children and she could not hide her surprise. When I asked why she seemed to be shocked by me having children, she unhesitantly stated she assumed that because I was in a wheelchair she did not think I could have children. This is the general perception of society. So, this project is critical to create awareness around disability. That persons with disabilities are much more than meets the eye, we are who encompass 
roles that makes us mothers, lovers, friends...the list is never ending. I'm so glad to have been part of this project. I'm glad that I could contribute to hopefully making a difference in how persons with disabilities are viewed - not just as people who need care, but as whole people with needs as all other people have."

\section{A Note on the Work Which Needs to Be Done}

The lessons about participation are perhaps the most valuable from this study and this book. But the content of the findings also bears revisiting here. And, the chapters of this book provide a useful framework on which to hang some of our ideas about what needs to be done in research, practice, and participatory work concerning physical disability and sexuality. These ideas are the result of the academic and disability organisation research teams' reflections, as well as anecdotes shared by participants. Chapter I was about this project-so the question to be raised is, what kind of research needs to be done in the future? In the realm of sexuality and disability research in the country, it would be extremely interesting and valuable, going forward, for there to be more work with people with disabilities from other ethnic, cultural, and socioeconomic backgrounds, and other geographic areas, as well as other gender identities, and sexual orientations, to those included in this project and book. The value of research like that upon which this project is based is in diversity and representation. So, the short answer to what kind of research is needed, is: more research.

Chapter 2 shared some more background about this study, but also reflected on our findings regarding people without disability's attitudes towards the sexuality of people with disabilities. Changing attitudes is complicated, and some of the work which must be done to achieve inclusive, equitable attitudes towards people with physical disabilities will rely on shifting conceptions of the sexuality of people with physical disabilities. The automatic assumption that people with physical disabilities are somehow not sexual, could be shifted through representation (popular culture showing more people with disabilities in normative romantic and social roles), as well as through more projects such as this one, which seeks to share stories as a way to raise awareness. However, to really promote intimate citizenship for people with physical disabilities, it will also be important to shift how people without disability-and society as a whole-represents sexuality. As long as sexuality is represented and 
thought about as something which only fit, young, attractive, people without disability can optimally 'achieve', attitudes towards the sexuality of people with physical disabilities will unlikely change (Hunt, 2018).

Chapter 3, Rosabelle's story, showcases the fundamental importance of inclusion in all areas of life, for people with physical disabilities' sense of themselves, including in seemingly unrelated areas. In countries like South Africa where inequalities in access to citizenship and participation are rampant, the project of inclusion and accessibility is a fundamentally important one. Opportunities for people with physical disabilities to achieve as great a degree of independence and participation as possible will be central to their capacity to achieve inclusion.

In Chapters 4 and 6, we spoke about femininity and masculinity, respectively. What each of these chapters, and the stories shared by Cleone, Bongani, and Vic, in their respective chapters, showcase, is the imperative of shifting attitudes to people with disabilities, and thinking about gender and expectations for gender roles, when people are young. All of these co-author participants spoke about the role which their socialisation had played in making difficult their experience of physical disability. Primarily this was due to their expectations for what 'normal' (without disability) men and women were expected to be and do, and their feelings of not measuring up to this in some way. As Chapter 6 illustrates, much of what needs to be done to shift these narrow and constraining conceptions of gender, will entail social movements around gender and sexuality which include people with disabilities (including physical disabilities), and movements around disability which include people with a broad array of gender identifications. As noted, a limitation of our work in this project is the absence of transgender and LGBTQ+ voices. Future research work could usefully examine how LGBTQ+ experiences of people with physical disabilities in South Africa. Exclusion is often a multilayered phenomenon, and so the voices of people who are minorities in more than one area (as people with disabilities and as sexual minorities) are vitally important to the project of inclusion.

In Chapter 8, we reflect on the state of SRH access for people with physical disabilities, with a focus on South Africa. One of the greatest learnings from the Disability o sexuality project had to do with the immense lack of epidemiological data about SRH for people with physical disabilities, and the SRH of people with physical disabilities. This kind of data could include information such as: 
1. How many of the women who give birth in South Africa every year are women with physical disabilities?

2. How many of the women who file a sexual assault complaint in South Africa every year are women with physical disabilities?

3. How many of the people who access contraceptive services in South Africa every year are people with physical disabilities?

4. Of all of the children and adolescents with physical disabilities in South Africa, how many have received comprehensive sexual education?

The fact that we cannot really answer any of these questions is a considerable problem for those of us who want to provide services for people with physical disabilities. Until the scope of the need is established, it is hard to pitch services. While studies such as the one upon which this book is based are important for reasons of inclusion and voicing, largescale epidemiological studies are very important too, and public health as a field could contribute a lot to understanding the needs of people with disabilities in South Africa, and other low- and middle-income countries.

The research results from this study, the stories shared, and the conclusions of this work all point to the need to think about recent theorisations of intimate citizenship by Ignagni, Shromans, Liddiard, and RunswickCole (2016). 'Intimate citizenship' concerns our rights, responsibilities, and agency to make personal and private decisions about with whom and how we are intimate, when we share intimacy, and why (Plummer, 2001).

As Hunt (2018) noted, the right to intimate citizenship, for people with physical disabilities, is impinged upon by the thoughts, feelings, and actions of non-disabled people (and internalisations of disablist attitudes). Ignagni et al. (2016) wrote, about intellectual disability, that intimate citizenship is fragile in the lives of labelled people' (p. 132). This seems to be true in the lives of South African people with physical disabilities. If people with physical disabilities continue to be excluded from dominant conceptions of sexuality and excluded from services and relationships, and as a consequence to feel 'less than' people without disability, their intimate citizenship will continue to be precarious.

This matters because, as Hunt (2018) notes, intimate, equitable relationships play a dominant role in securing the social support and capital which support activity in numerous other facets of existence, including safety and security, and accessing important resources (Ignagni et al., 2016). Equitable intimate relationships and partnerships are also a source 
of support against violence and discrimination, experiences to which people with physical disabilities in South Africa are all too vulnerable (Astbury \& Walji, 2014; Hunt, 2018). As such, the attitudinal barriers described by the participants in this study, and revealed in the survey, may have very real social and economic costs for people with physical disabilities (Hunt, 2018).

\section{Concluding Notes and Take-Home Points}

What this project highlights is that these issues of sexual recognition and exclusion are issues of citizenship and justice, and part of the solution to injustices involves collaboration and creativity. The process of doing work that is participatory, requires creativity. Much of the process of working together on this project, and writing this book, evolved over time. It required us to be surprised and discover new ideas along the way. It required us to be challenged and to learn along the way. Above all it required us to enjoy working together and learning from one another. We hope that this has been reflected in this book, and that, in turn, you the reader have been surprised, challenged, and inspired to learn something new.

\section{REFERENCES}

Astbury, J., \& Walji, F. (2014). The prevalence and psychological costs of household violence by family members against women with disabilities in Cambodia. Journal of Interpersonal Violence, 29(17), 3127-3149.

Charlton, J. I. (1998). Nothing about us without us: Disability oppression and empowerment. Berkeley, CA: University of California Press.

Garland-Thomson, R. (2005). Feminist disability studies. Signs: Journal of Women in Culture and Society, 30(2), 1557-1587.

Hunt, X. (2018). Through a different lens: Examining commonality and divergence in constructions and depictions of the sexuality of persons with physical disabilities in South Africa (PhD Dissertation). South Africa: Stellenbosch University.

Ignagni, E., Fudge Schormans, A., Liddiard, K., \& Runswick-Cole, K. (2016). 'Some people are not allowed to love': Intimate citizenship in the lives of people labelled with intellectual disabilities. Disability \& Society, 31(1), 131135 . 
Plummer, K. (2001). The square of intimate citizenship: Some preliminary proposals. Citizenship studies, 5(3), 237-253.

Swartz, L., van der Merwe, A., Buckland, A., \& McDougall, K. L. (2012). Producing boundary-breaking texts on disability issues: The personal politics of collaboration. Disability and Rebabilitation, 34, 951-958. https:// doi.org/10.3109/09638288.2011.624248.

United Nations. (2006). Convention for the rights of persons with disability (UNCRPD). Retrieved from https://www.un.org/development/desa/disabi lities/convention-on-the-rights-of-persons-with-disabilities/convention-onthe-rights-of-persons-with-disabilities-2.html.

Open Access This chapter is licensed under the terms of the Creative Commons Attribution 4.0 International License (http://creativecommons.org/licenses/ by $/ 4.0 /)$, which permits use, sharing, adaptation, distribution and reproduction in any medium or format, as long as you give appropriate credit to the original author(s) and the source, provide a link to the Creative Commons license and indicate if changes were made.

The images or other third party material in this chapter are included in the chapter's Creative Commons license, unless indicated otherwise in a credit line to the material. If material is not included in the chapter's Creative Commons license and your intended use is not permitted by statutory regulation or exceeds the permitted use, you will need to obtain permission directly from the copyright holder.

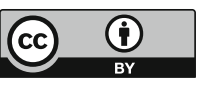

